\title{
Todos nuestros huesos: ciencia racial y sexualidad en la Argentina finisecular
}

\author{
All our bones: racial science and sexuality \\ in turn-of-the-century Argentina
}

\author{
Patricio Simonetto ${ }^{i}$ \\ ' Consejo Nacional de Investigaciones Científicas y Técnicas \\ Buenos Aires - Argentina \\ https://orcid.org/0000-0001-5906-7072 \\ patriciosimonetto@gmail.com
}

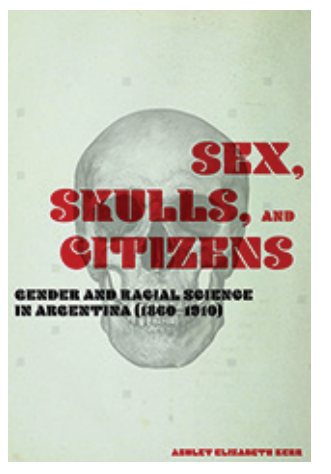

Kerr, Ashley Elizabeth. Sex, skulls, and citizens: gender and racial science in Argentina (1860-1910). Nashville: Vanderbilt University Press, 2020. 240p.
Todos nuestros huesos persisten al paso del tiempo. Son los últimos registros del archivo viviente que llamamos cuerpo. Frágiles e indestructibles, los restos óseos resisten archivados bajo tierra (o minan) nuestro vínculo con el pasado. Esto parece aún más evidente en una Argentina en la que los restos humanos se han transformado en poderosos agentes de las narrativas históricas. Quizás un ejemplo paradigmático de esto sean los restos de las víctimas del terrorismo de Estado de la última dictadura militar, que, activados por los equipos de antropología forense y los organismos de derechos humanos, se transformaron en actores indiscutibles en los procesos por la verdad, la memoria y la justicia.

Sex, skulls and citizens aborda otros restos: aquellos que durante décadas permanecieron como botines de guerra en las vitrinas de los museos. Este libro se ocupa de aquellos cuerpos violentados por el proyecto expansionista del Estado argentino para indagar sobre los puntos de contacto entre ciencia, raza y sexualidad en la formación de la argentina moderna.

Ashley Elizabeth Kerr explora de forma novedosa el universo de las ciencias raciales y su rol en la construcción de la narrativa de la Argentina blanca y las normas de género. Este libro se suma a importantes estudios de la última década que abordaron el papel de la blanquitud en la cultura argentina (Alberto, Elena, 2016; Edwards, 2020). En este sentido, Kerr explora documentos considerados clásicos por la historiografía como Una excursión a los indios ranqueles, de Lucio Mansilla, los registros fotográficos del Museo de la Plata o las gestiones de su director Francisco Moreno con un acento en el papel de las prácticas sexuales de los indígenas en la construcción y circulación de imaginarios raciales.

Sex, skulls and citizens desmitifica la producción de conocimiento decimonónica. En este libro, el conocimiento no se reduce a un sistema de ideas. Por el contrario, es un campo vivo 
de intervención en el que se articulan prácticas eróticas, visiones del mundo y en el que las divisiones entre la vida íntima y públicas se tornan ficticias. Los agentes del conocimiento abandonan así toda pretensión neutral: son seres de carne y hueso complejos, con ricas vidas íntimas que intervienen su producción intelectual y a los que Kerr posiciona en los conflictos por la definición del futuro de la joven nación.

Sex, skulls and citizens coloca al cuerpo femenino en el centro de la constitución de los discursos raciales. La autora desmonta así las representaciones de las mujeres como agentes pasivos en la producción de conocimiento. Por el contrario, rescata las complejas formas de agencia con el que estas mujeres modularon los imaginarios raciales y sexuales. Desde las relaciones de mujeres Tehuelches con los antropólogos del Estado argentino hasta el rol de las mujeres blancas en la apropiación de niños indígenas para su colocación como mano de obra barata de las familias acomodadas, el texto restablece el diverso universo femenino en el que se entretejieron jerarquías fundacionales de la cultura argentina.

Ashley Elizabeth Kerr demuestra cómo los imaginarios de la nación argentina desplegaron fecundos imaginarios de futuro en torno a la reproducción heterosexual y la familia. En su libro, la sexualidad se interconecta con la raza para recordarnos las siempre latentes ansiedades de las elites argentinas por moldear una nación imaginada como blanca, por lo tanto, de disputar los cuerpos de las madres en los que se gestarían las futuras generaciones. En este sentido, el cuerpo mesurado de las indígenas es un laboratorio en el que se producen ideas de la otredad, mientras que el de las mujeres blancas es representado como un tesoro preciado y asediado por una sexualidad indígena imaginada como peligrosa, siempre a riesgo de contaminar a las futuras generaciones y de atrofiar así el desarrollo nacional.

Sex, skulls and citizens analiza el papel de la representación del cuerpo indígena como un elemento fundamental de los proyectos de racialización argentina. Kerr demuestra cómo la formación de fronteras raciales estuvo profundamente vinculada con la categorización del cuerpo indígena como representante de una otredad que la civilización debía superar. De este modo la autora recorre como la masculinidad indígena representó figuras paradójicas como su supuesta improductividad, infantilismo y a la vez como portadores de una sexualidad perturbadora e incontrolable. Kerr analiza así las ansiedades encarnadas por el proyecto de la Argentina blanca: la angustia por los supuestos efectos perniciosos del mestizaje y los deseos por la primacía blanca como garantía de futuro.

Kerr argumenta con inteligencia como el contacto sobre la sexualidad y la raza articularon diversas temporalidades. Las ciencias raciales se construyeron bajo la idea de que las comunidades originarias eran parte de un pasado que la nación argentina dejaría atrás mediante la civilización. Sus cuerpos (y sus restos) fueron entonces administrados como el ejemplo de un mundo del que debíamos distinguirnos para devenir modernos. El mestizaje era para ellos un peligro que atentaba contra el futuro del desarrollo nacional, una invasión al territorio del cuerpo femenino que podría acabar con los sueños de la élite argentina.

Sex, skulls and citizens es un libro atrapante y con una escritura cuidada que contribuye a varios campos de conocimiento. Una investigación aguda que interconecta documentos centrales para la historiografía argentina con las nuevas perspectivas materialistas de la fotografía. Obra que se consagrará como un clásico para quienes estén interesados en los 
estudios latinoamericanos, literarios, la historia argentina, la racialización, sexualidad o las culturas visuales. Un recuerdo punzante acerca de cómo los imaginarios sobre la intimidad son constitutivos de nuestros lazos sociales.

\section{REFERÊNCIAS}

ALBERTO, Paulina; ELENA, Eduardo. Rethinking race in modern Argentina. New York: Cambridge University Press, 2016.

EDWARDS, Erika Denise. Hiding in plain sight: black women, the law, and the making of a white
Argentine Republic. Tuscaloosa: University Alabama Press, 2020.

KERR, Ashley Elizabeth. Sex, skulls, and citizens: gender and racial science in Argentina (1860-1910). Nashville: Vanderbilt University Press, 2020.

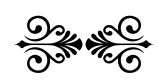

